\title{
Proof of Concept Evaluation of a New Diagnostic POCT Device for Culture- Independent Microbiological Diagnosis of Infective Endocarditis
}

\author{
Matthias Karrasch ${ }^{1} 2^{*}$, Wolfgang Pfister ${ }^{1}$, Mahmoud Diab $^{3}$, Torsten Doenst ${ }^{3}$, Bettina Löffler ${ }^{1}$ and \\ Jürgen Rödel ${ }^{1}$
}

${ }^{1}$ Institute of Medical Microbiology, Jena University Hospital, Jena, Germany

${ }^{2}$ Institute of Clinical Chemistry \& Laboratory Medicine, Jena University Hospital, Jena, Germany

${ }^{3}$ Department of Cardiothoracic Surgery, Jena University Hospital, Jena, Germany

*Corresponding author: Matthias Karrasch, Institute of Medical Microbiology, Jena University Hospital, Jena, Germany, Tel: +49/3641-9325073; Email: matthias.karrasch@med.uni-jena.de

Received date: February 13, 2019; Accepted date: February 20, 2019; Published date: February 26, 2019

Citation: Karrasch M, Pfister W, Diab M, Doenst T, Löffler B, et al. (2019) Proof of Concept Evaluation of a New Diagnostic POCT Device for CultureIndependent Microbiological Diagnosis of Infective Endocarditis. Arch Clin Microbiol Vol.10 No.1:88

Copyright: (c) 2019 Karrasch M, et al. This is an open-access article distributed under the terms of the Creative Commons Attribution License, which permits unrestricted use, distribution, and reproduction in any medium, provided the original author and source are credited.

\section{Abstract}

Introduction: Accurate and fast microbiological diagnosis of infective endocarditis (IE) is of vital importance for patient outcome.

Material \& Methods: Forty culture-negative heart valves were evaluated with a new POCT multiplex-PCR cartridge (Unyvero ${ }^{\mathrm{TM}}$, Curetis AG, Holzgerlingen, Germany), advertised to detect several Gram positive/negative bacteria and fungi, together with several antibiotic resistance genes. Those POCT results were compared to conventional 16S rDNA $\mathrm{PCR} /$ sequencing results.

Results: POCT multiplex-PCR was positive in 13 cases [Staphylococcus aureus $(n=5)$, Enterococcus spp. / $E$. faecalis $(n=5)$, ConS $(n=1)$, Granulicatella adjacens $(n=1)$, Abiotrophia adjacens $(n=1)]$. Antibiotic resistances were found in 44 specimens, from which 2 specimens were without any pathogen identification. 16S rDNA PCR was positive in 20 cases. Consecutive sequencing identified those as Staphylococcus spp. $(n=6)$, Enterococcus faecalis $(n=4)$, Streptococcus spp. $(n=4)$, Leifsonia shinshuensis $(n=1)$, Granulicatella elegans / $G$. adjacens $(n=2)$, Abiotrophia adjacens $(n=1)$. One case was positive in $16 S$ PCR without any reliable signal in sequencing. When comparing both methods, identification was consistent in 9 cases and divergent in other 9 cases.

Discussion: This POCT cartridge is easy to integrate into the daily microbiology laboratory work flow, and is less laborious than $16 \mathrm{~S}$ sequencing PCR. For the application in routine IE diagnosis, the system needs to be optimized to include targets for viridans streptococci and HACEK group. In addition, problems with invalid resistance and pathogen target detection need to be fixed by the producer.
Conclusion: The analyzed POCT system might be a future diagnostic tool for IE detection following assay optimization.

Keywords: POCT; Microbiological diagnosis; Endocarditis; Antibiotic resistance

\section{Introduction}

Infective endocarditis (IE) is a serious disease with a high mortality rate [1] and accurate and fast microbiological diagnosis of IE is of vital importance for patient outcome. IE is difficult to diagnose as blood cultures and culture from heart valve tissue samples often remain negative, mainly due to previous microbial treatment or fastidious IE causing microorganisms (e.g. Bartonella sp., Coxiella burnetti, Tropheryma whipplei). For the culture identification of IE-causing HACEK (Aggregatibacter aphrophilus, Cardiobacterium hominis, Eikenella corrodens, Kingella kingae) bacteria and streptococci, a prolonged incubation for 7-14 days is often needed for identification [2]. Although the modified Duke criteria (DC) have been established for the diagnosis of IE, they have limitations in the diagnosis of IE in prosthetic valves and intra cardiac devices [3]. The yearly rate of IE in patients with a prosthetic valve is approximately 3 cases per 1,000 patients [4]. PCR may offer significant advantages in diagnosis due to the generation of fast results [5]. The correct identification of IE-causing pathogens is important for immediate targeted antibiotic therapy and the avoidance of unnecessary antibiotics, in the context of antibiotic stewardship (ABS) programs. Overall, there is a high need for optimized and faster molecular detection assays for early and targeted treatment of IE-causing pathogens [6-8]. 


\section{Materials and Methods}

\section{POCT multiplex-PCR assay and conventional diagnosis}

We performed an evaluation that examined the sensitivity and specificity of a new point of care testing (POCT) multiplex PCR assay (Unyvero ${ }^{\mathrm{TM}}$, Curetis, Holzgerlingen, Germany) for swift detection of causative microbes in culture-negative cases of IE. The Unyvero $^{\mathrm{TM}} \mathrm{i} 60 \mathrm{ITI}$ cartridge is advertised to detect several Grampositive/-negative bacteria and fungi in implant and tissue, together with some of the most important antibiotic resistance genes. Specimens from 40 fresh frozen heart valves were cultured on Columbia/chocolate agar plates and incubated in brain-heart broth for 7 days. In cases of no bacterial growth after $24 \mathrm{~h}$, tissue specimens were evaluated with the new POCT multiplex-PCR assay for the detection of heart valve infections and compared to $16 \mathrm{~S}$ rDNA PCR results. In cases of pathogen growth after $>24$ hours, identification of colonies was performed using MALDI-TOF (VITEK MS) or VITEK 2 technology. Heart valves were frozen after culture inoculation and thawed after $24 \mathrm{~h}$ for lysis in the POCT lysator which is able to process a wide range of clinical sample types using a standardized protocol. The Unyvero $^{\mathrm{TM}}$ sample tube prepares the patient sample containing glass beads and buffers for bacterial lysis and sample liquefaction. The Unyvero $^{\mathrm{TM}}$ i60 ITI cartridge is equipped with integrated reagent containers, a DNA purification column, eight separate PCR chambers and a corresponding number of arrays. The cartridge contains buffers for DNA purification, reagents and fluorescence-marked primers for PCR amplification, as well as probes for array hybridization and is assembled by inserting the Unyvero $^{\mathrm{TM}}$ sample tube with the lysed sample and the master mix tube. Once assembled, the cartridge is physically closed, minimizing the risk of contamination. An internal control is also included in the cartridge in order to verify the DNA purification, PCR and array hybridization for each measurement. This gene is amplified in each of the eight PCR chambers and hybridized on each array The Unyvero ${ }^{\mathrm{TM}}$ analyzer processes up to two Unyvero ${ }^{\mathrm{TM}}$ Cartridges in random access mode and automatically performs DNA purification, specific amplification and detection. The Unyvero $^{\mathrm{TM}}$ cockpit is equipped with a touchscreen and connects the Unyvero ${ }^{\mathrm{TM}}$ analyzer to the lysator. Resistance genes that can be measured included mec $A / C$ (resistance to methicillin, and other B-lactams), van A/B (resistance to glycopeptides), erm A/C (erythromycin-resistance genes), $\mathrm{vim} / \mathrm{imp} / \mathrm{kpc} / \mathrm{ndm}$ (carbapenemases, metallo- $\beta$-lactamases), aacA4 (aminoglycoside 6'-N-acetyltransferase, resistance-modifying enzyme gene), ctx-M (most prevalent extended-spectrum betalactamases), rpoB oxa-23/-24/-48/-58(carbapenemases), gyrA (quinolone-resistance), $\operatorname{aac}\left(6^{\prime}\right) / \mathrm{aph}\left(2^{\prime \prime}\right)$ (aminoglycoside-6'-Nacetyltransferase/2"-O-phosphoryltransferase).

\section{S PCR/sequencing}

Bacterial DNA was automatically extracted by the Maxwell Tissue DNA Purification Kit on a Maxwell 15 machine (Promega, Mannheim, Germany). Amplification was performed using the Multiplex PCR Kit (Qiagen, Hilden, Germany) and the ligonucleotides 16S-F (5' TGGTAGTCCACGCCGTAACC 3') and 16S-GRP-R (5' TCATAAGGGGCATGATGAT 3') to detect Gram positive pathogens or 16S-GRN-R (5' CGTAAGGGCCATGATGACT $\left.3^{\prime}\right)$ to detect Gram negative pathogens, respectively. The amplification was carried out on a Master cycler epi gradient $\mathrm{S}$ (Eppendorf, Hamburg, Germany) with the following conditions: initial denaturation at $95^{\circ} \mathrm{C}$ for $15 \mathrm{~min}, 35$ cycles of $94^{\circ} \mathrm{C}$ for 15 sec and $53^{\circ} \mathrm{C}$ for $15 \mathrm{sec}$ and $72^{\circ} \mathrm{C}$ for $1 \mathrm{~min}$, followed by terminal elongation at $72^{\circ} \mathrm{C}$ for $5 \mathrm{~min}$. The quality of each PCR run was ensured by negative control, positive control (DNA of M.luteus for Gram-positive PCR and DNA of M.catarrhalis for Gramnegative $P C R$ ) and inhibition control.

All PCR amplicons obtained from patient samples were subject to sequencing in both sense and antisense directions performed with a Big Dye Terminator v1.1 cycle sequencing kit and an $A B I$ Prism 310 sequencer (Applied Bio systems, Foster City, CA, USA) according to standard protocols. Sequencing was performed by using forward and reverse primers (10 pmol each). PCR amplicons were purified from the gel with an Invisorb spin DNA extraction kit (Invitek, Berlin, Germany), and further treated with the sequencing kit material. The following program was executed: 1 cycle at $96^{\circ} \mathrm{C}$ for $1 \mathrm{~min}$ and 25 cycles of $96^{\circ} \mathrm{C}$ for $10 \mathrm{~s}, 50^{\circ} \mathrm{C}$ for $5 \mathrm{~s}$, and $60^{\circ} \mathrm{C}$ for $4 \mathrm{~min}$. The electropherog rams obtained were analyzed using sequencing analysis software (version 3.7; Applied Biosystems). The results were aligned and examined by Gen Bank NCBI genetic sequence database searching.

\section{Results}

Fresh frozen heart valves were examined in routine bacteriology laboratory and with the Unyvero ${ }^{\mathrm{TM}}$ i60 ITI Cartridge.

The ITI cartridge signal was positive in 13 cases [Staphylococcus aureus $(\mathrm{n}=5)$, Enterococcus spp. / E. faecalis $(n=5)$, Cons $(n=1)$, Granulicatella adjacens $(n=1)$, Abiotrophia adjacens $(n=1)$ ] and negative in 27 cases. Problems with invalid targets measuring the full resistance panel occurred in 11 out of 40 cartridges. Antibiotic resistances were found in 4 specimens [1: vanB, rpoB, oxa-58, ndm; 2: ermC, oxa-48, aacvA4; 3: rpoB; 4: $\operatorname{aac}(6) / a p h(2))$. From these, two specimens $(1 ; 2)$ were without any pathogen identification. The detected pathogen related to the detected rpoB resistance was $S$. aureus and the detected species related to the detected aac(6)/aph(2) resistance was $E$. faecalis. 16S rDNA PCR was negative in 20 cases, and positive in 20 cases (Table 1). All 20 amplificates were sequenced, 19 of them were identified as Staphylococcus spp $(\mathrm{n}=6)$, Enterococcus faecalis $(n=4)$, Streptococcus spp. $(n=4)$, Leifsonia shinshuensis $(n=1)$, Granulicatella elegans / $G$. adjacens $(n=2)$, Abiotrophia adjacens $(n=1)$. One case was positive in $16 S$ PCR without signal in sequencing. When comparing $16 \mathrm{~S}$ PCR results to Unyvero results, identification was consistent in 9 cases ( $4 \times$ for $E$. spp./ E.faecalis, $3 \times$ for $S$. aureus, $1 \times$ for Granulicatella adjacens, $1 \times$ for Abiotrophia adjacens) and divergent in 9 cases $(2 \mathrm{x}$ Streptococcus spp. (Seq.) versus $2 \times$ S. aureus (ITI), $2 \times$ Streptococcus spp. (Seq.) versus negative result (ITI), $1 \mathrm{x}$ Leifsonia (seq.) vs. negative result (ITI); $3 \times$ S. aureus (seq). vs. negative (ITI); $1 \times$ Granulicatella adjacens (seq) vs. negative result (ITI). Bacteria from the HACEK group and Streptocci (with the exception of group A and B streptococci) are not covered in 
the ITI panel. Sensitivity/specificity analysis was not applied due to the small amount of specimen tested.

Table 1. Microorganisms and resistance markers detected by the Unyvero ITI Panel.

\begin{tabular}{|c|c|}
\hline Group & Pathogen \\
\hline \multirow{5}{*}{ Gram-positive bacteria } & Staphylococcus aureus \\
\hline & Coagulase negative staphylococci [15] \\
\hline & Streptococcus agalactiae \\
\hline & Streptococcus pyogenes [14] \\
\hline & Enterococcus faecalis \\
\hline \multirow[b]{2}{*}{ Nutritionally variant streptococci } & Granulicatella adiacens \\
\hline & Abiotrophia defectiva \\
\hline Corynebacteriaceae & Corynebacterium spp [16] \\
\hline \multirow[b]{6}{*}{ Enterobacteriaceae } & Escherichia coli \\
\hline & Enterobacter cloacae complex \\
\hline & Enterobacter aerogenes \\
\hline & Proteus spp. [1] \\
\hline & Klebsiella pneumonia [17] \\
\hline & Klebsiella oxytoca \\
\hline \multirow[b]{2}{*}{ Nonfermenters } & Pseudomonas aeruginosa \\
\hline & Acinetobacter baumannii complex \\
\hline \multirow[b]{4}{*}{ Anaerobic bacteria } & Propionibacterium acnes \\
\hline & Propionibacterium avidum+/granulosum ${ }^{*}$ \\
\hline & Finegoldia magna \\
\hline & Bacteroides fragilis group [6] \\
\hline \multirow[b]{2}{*}{ Fungi } & Candida parapsilosis \\
\hline & Candida albicans \\
\hline marker & Resistance \\
\hline $\operatorname{mec} A$ & Oxacillin/methicillin \\
\hline mecC (LGA251) & Oxacillin/methicillin \\
\hline $\operatorname{aac}\left(6^{\prime}\right) / \operatorname{aph}\left(2^{\prime \prime}\right)$ & Aminoglycosides \\
\hline ermA & Macrolides/lincosamides \\
\hline ermC & Macrolides/lincosamides \\
\hline vanA & Vancomycin \\
\hline vanB & Vancomycin \\
\hline rpoB & Rifampin \\
\hline ctx-M & 3 rd generation cephalosporins \\
\hline Vim & Carbapenem \\
\hline Imp & Carbapenem \\
\hline $\mathrm{Kpc}$ & Carbapenem \\
\hline
\end{tabular}




\begin{tabular}{|l|l|}
\hline Ndm & Carbapenem \\
\hline aacA4 & Aminoglycosides \\
\hline gyrA (Escherichia coli) & Fluoroquinolones \\
\hline oxa-23 & Carbapenem \\
\hline oxa-24 & Carbapenem \\
\hline oxa-48 & Carbapenem \\
\hline oxa-58 & Carbapenem \\
\hline
\end{tabular}

\section{Discussion}

PCR testing of explanted heart valves is recommended in addition to culture techniques to increase diagnostic yield [9]. In case of negative culture result, current guidelines recommend that tissues from excised heart valves or vegetations from patients with suspected IE should be referred for broad-range bacterial PCR and sequencing [10]. Unfortunately, this 16S PCR is prone to contamination of reagents with bacterial DNA, which represents a major problem exacerbated by the highly sensitive nature of 16S PCR. These methods are also laborious and time- consuming, thus fully-automated assays which can be easily integrated in the routine work flow are needed. This evaluation highlights the importance of molecular analysis in diagnostically challenging culture-negative IE as time to result is of critical importance in the diagnosis of IE. For the majority of pathogens detected in this study, the information provided by the new POCT seems to be sufficient in the first place, given the high incidence of staphylococci, streptococci and enterococci in this disease. Although bacteria from the HACEK group were not discovered with $16 \mathrm{~S}$ PCR IE, they should be covered by a POCT system, despite their rareness (Table 2 ).

Table 2. comparison results between conventional bacteriology, $16 \mathrm{~S}$ PCR/sequencing and POCT.

\begin{tabular}{|c|c|c|c|c|}
\hline No & Conventional bacteriology & 16S PCR /sequencing & POCT result & POCT resistence genes \\
\hline 1 & E. faecalis & positive /Enterococcus spp. & Enterococcus spp. & - \\
\hline 2 & no growth & $16 S$ & PCR: negative & - \\
\hline 3 & no growth & $16 S$ & PCR: negative & vanB, rpoB, oxa-58, ndm \\
\hline 4 & no growth & $16 S$ & PCR: negative & - \\
\hline 5 & no growth & $16 S$ & PCR: negative & - \\
\hline 6 & no growth & $16 S$ & PCR: negative & ermC, oxa-48, aacvA4 \\
\hline 7 & no growth & $16 \mathrm{~S}$ & PCR: negative & - \\
\hline 8 & no growth & $16 S$ & PCR: negative & - \\
\hline 9 & E. faecalis & positive / E. faecalis & & - \\
\hline 10 & no growth & positive / Streptococcus spp. & S.aureus & - \\
\hline 11 & S. aureus & positive / Streptococcus spp. & S. aureus & \\
\hline 12 & no growth & positive / S. spp. (S. aureus/S. haemolyticus & negative & - \\
\hline 13 & no growth & 16S PCR: negative & negative & - \\
\hline 14 & no growth & positive / Leifsonia shinshuensis & negative & - \\
\hline 15 & no growth & positive / S. aureus/ S. haemolyticus & S. aureus & - \\
\hline 16 & no growth & positive / S. aureus/ S. haemolyticus) & S. aureus & - \\
\hline 17 & no growth & positive / S. sanguinis & negative & - \\
\hline 18 & no growth & positive / S. aureus & S. aureus & rpoB \\
\hline 19 & no growth & positive / G. elegans & Enterococcus spp. & - \\
\hline 20 & no growth & positive / $A$. adjacens & A. defectiva & - \\
\hline 21 & no growth & positive / Staphylococcus spp. & negative $(2 x)$ & - \\
\hline
\end{tabular}




\begin{tabular}{|c|c|c|c|c|}
\hline 22 & no growth & 16S PCR: negative & negative & - \\
\hline 23 & C. striatum P. acnes & 16S PCR: negative & negative & - \\
\hline 24 & & & CoNS & - \\
\hline 25 & no growth & positive / G. adjacens & G. adjacens & - \\
\hline 26 & no growth & positive / S. sanguinis/mitis & negative & - \\
\hline 27 & E. faecalis & positive / Enterococcus spp. & $\begin{array}{l}\text { E. faecalis } \\
\text { E. spp. }\end{array}$ & $\operatorname{aac}(6) / a p h(2)$ \\
\hline 28 & E. faecalis & positive / Enterococcus spp & $\begin{array}{l}\text { E. faecalis } \\
\text { E. spp. }\end{array}$ & \\
\hline 29 & no growth & positive & negative & - \\
\hline 30 & no growth & 16S PCR: negative & negative & \\
\hline 31 & no growth & 16S PCR: negative & negative & - \\
\hline 32 & no growth & positive / Staphylococcus spp. & negative & - \\
\hline 33 & no growth & 16S PCR: negative & negative & - \\
\hline 34 & no growth & 16S PCR: negative & negative & - \\
\hline 35 & no growth & 16S PCR: negative & negative & - \\
\hline 36 & no growth & 16S PCR: negative & negative & - \\
\hline 37 & no growth & 16S PCR: negative & negative & - \\
\hline 38 & no growth & 16S PCR: negative & negative & - \\
\hline 39 & no growth & 16S PCR: negative & negative & - \\
\hline 40 & no growth & 16S PCR: negative & negative & - \\
\hline
\end{tabular}

The detection of 5 staphylococcal cases using multiplex PCR assay is not surprising, as Staphylococcus aureus is described as the most common cause of IE in the developed world [11]. There was only a slight difference in the absolute numbers of staphylococcal cases using 16S rDNA PCR/sequencing (6 cases, although Staphylococcus spp in 6 cases. Streptococcal species are common causative IE pathogens [7]. This is in line with our finding of 4 streptococcal cases in this evaluation. Accurate identification within some streptococcal groups was limited with both techniques used. In case of divergent results, such results should be interpreted with caution. Biochemical streptococcal species identification were shown to result in false identifications in more of half of the patients when compared to genetic discrimination methods (Table 3). Nutritionally variant streptococci (Abiotrophia defective or Granulicatella spp.), are thought to account for $2 \%$ of all infective endocarditis cases [12]. Due to difficulties in obtaining positive microbiology cultures, Granulicatella adjacens is known to be responsible for culture-negative infective endocarditis [13]. Both methods used in this evaluation were convergent for Abiotrophia spp, and one Granulicatella case, but divergent for 2 other cases of Granulicatella.

Thus these two results should be interpreted with caution. Infections caused by multi-resistant enterococci ( $E$. faecium, $E$. faecalis) have increased over the recent years to a point that they now represent the 3rd most common cause of IE worldwide [14].

Table 3. Overall Comparison of POCT results to Standard conventional $16 \mathrm{~S} \mathrm{PCR} /$ Sequencing results.

\begin{tabular}{|l|l|}
\hline Results & N \\
\hline Convergent negative with both methods & 20 \\
\hline Convergent positive with both methods & 9 \\
\hline 16S PCR positive / Unyvero negative & 6 \\
\hline 16S PCR negative / Unyvero positive & 1 \\
\hline divergent positive results & 3 \\
\hline true negative & 21 \\
\hline true positive & 18 \\
\hline false negative & 6 \\
\hline false positive & 4 \\
\hline
\end{tabular}

This is also reflected in our evaluation. Unlike streptococci and taphylococci, most enterococci do not produce a set of potent pro-inflammatory toxins, but they are equipped with many genes encoding adhesion proteins that may mediate adherence to host tissues, consistent with their pathogenic role in infective 
endocarditis. Vancomycin-resistnat E. faecium (VRE) is difficult to treat [15].

\section{Conclusion}

The Unyvero ITI cartridge could represent a useful tool for IE diagnosis. It can be easily integrated into the lab work flow and is less laborious. However, for its application in routine IE diagnosis the multiplex system needs to be optimized and extended to include targets for viridans streptococci and the HACEK group. Therefore, a new specific IE cartridge needs to be developed. In addition, problems with invalid resistance and pathogen target detection need to be fixed before routine testing.

\section{Acknowledgement}

Preliminary data of this work were demonstrated in part as poster presentation at the 2015 Annual Meeting of the German Society of Hygiene and Microbiology (Deutsche Gesellschaft für Hygiene und Mikrobiologie; DGHM) in Münster, Germany. This evaluation was performed at the Institute of Medical Microbiology, Jena University Hospital, and supported by Curetis $A G$, the manufacturer of the molecular diagnostic prototype tool. POCT system and PCR cartridges were provided for free over a test period of six months.

\section{Conflict of Interest (COI) Statement}

All authors report no COI

\section{Ethical standards statement}

This evaluation has been approved by the appropriate ethics committee and have therefore been performed in accordance with the ethical standards laid down in the 1964 Declaration of Helsinki and its later amendments.

\section{References}

1. Palraj BR, Baddour LM, Hess EP, Steckelberg JM, Wilson WR, et al. (2015) Predicting Risk of Endocarditis Using a Clinical Tool (PREDICT): Scoring System to Guide Use of Echocardiography in the Management of Staphylococcus aureus Bacteremia. Clin Infect Dis. 235.

2. Tattevin P, Watt G, Revest M, Arvieux C, Fournier PE (2015) Update on blood culture-negative endocarditis (Les 8egatives8is à hémocultures 8egatives : mise au point) Médecine et maladies infectieuses 45 (2015) 1-8Teles C, Smith A, Ramage G, Lang S. Identification of clinically relevant viridans group streptococci by phenotypic and genotypic analysis. Eur J Clin Microbiol Infect Dis 30: $243-250$.

3. Pizzi $M N$, Roque $A$, Fernández-Hidalgo $N$, Cuéllar-Ca labria $H$, Ferreira-González I, et al. (2015) Improving the Diagnosis of
Infective Endocarditis in Prosthetic Valves and Intracardiac Devices with 18F-FDG-PET/CT-Angiography: Initial Results at an Infective Endocarditis Referral Center. Circulation.

4. Musso M, Petrosillo N (2015) Nuclear Medicine in Diagnosis of Prosthetic Valve Endocarditis: An Update. Biomed Res Int 1-7.

5. Naber CK, Erbel R (2007) Infective endocarditis with negative blood cultures. International Journal of Antimicrobial Agents 30: S32-S36.

6. Ipek EG, Guray Y, Acar B, Kafes H, Asarcikli LD, et al. (2015) The usefulness of serum troponin levels to predict 1-year survival rates in infective endocarditis. Int J Infect Dis 34: 71-75.

7. Murdoch DR, Corey GR, Hoen B, Miró JM, Fowler VG, et al. (2009) Clinical presentation, etiology, and outcome of infective endocarditis in the 21st century: the International Collaboration on Endocarditis-Prospective Cohort Study. Arch Intern Med 169: 463-473.

8. Marsch G, Orszag P, Mashaqi B, Kuehn C, Haverich A (2015) Antibiotic therapy following polymerase chain reaction diagnosis of infective endocarditis: a single centre experience. Interact Cardiovasc Thorac Surg 20: 589-593.

9. Harris KA, Yam T, Jalili S, Williams OM, Alshafi K, et al. (2014) Service evaluation to establish the sensitivity, specificity and additional value of broad-range 16S rDNA PCR for the diagnosis of infective endocarditis from resected endocardial material in patients from eight UK and Ireland hospitals. Eur J Clin Microbiol Infect Dis 33: 2061-2066.

10. Leli C, Moretti A, Pasticci MB, Cenci E, Bistoni F, Mencacci A (2014) A commercially available multiplex real-time PCR for detection of pathogens in cardiac valves from patients with infective endocarditis. Diagnostic Microbiology and Infectious Disease 79: 98-101.

11. Kasmi G, Refatllari E, Dumani S, Refatllari A (2014) Early infective endocarditis due to Staphylococcus aureus following dental procedures. Clin Lab 60: 1933-1936.

12. Rhodes HM, Hirigoyen D, Shabnam L, Williams DN, Hansen GT (2016) Infective endocarditis due to Abiotrophia defectiva and Granulicatella spp. complicated by infectious intracranial cerebral aneurysms: a report of three cases and review of the literature. J Med Microbiol 65: 493-499.

13. Quiroga B, Arroyo D, Verde E, Eworo A, Luño J (2012) Infective endocarditis on a percutaneous prosthetic aortic valve with associated glomerulopathy due to Granulicatella adjacens. Braz J Infect Dis16: 601-602.

14. Arias CA, Murray BE (2009) Antibiotic-resistant bugs in the 21st century--a clinical super-challenge. N Engl J Med 360: 439-443.

15. Arias CA, Murray BE (2012) The rise of the Enterococcus: beyond vancomycin resistance. Nat Rev Microbiol 10: 266-278.

16. Donlan RM, Costerton JW (2002) Biofilms: survival mechanisms of clinically relevant microorganisms. Clin Microbiol Rev 15:167-193.

17. Grisoli D, Million M, Edouard S, Thuny F, Lepidi H, et al. (2014) Latent $Q$ fever endocarditis in patients undergoing routine valve surgery. J Heart Valve Dis. 23: 735-743. 